\title{
Epidermal absorption in male scrotum of topical application of psychedelic drugs: times and effects
}

\section{Piotr Brzezinski', Lorenzo Martini ${ }^{1,2}$}

${ }^{1}$ University of Siena, Department of Pharmaceutical Biotechnologies, Via A. Moro 2, 53100 Siena, Italy, ${ }^{2}$ C.R.I.S.M.A. Inter

University Centre for Researched Advanced Medical Systems

Corresponding author: Prof. Lorenzo Martini, M.Sc., E-mail: martini36@unisi.it

\begin{abstract}
Scope of our paper is to demonstrate how a psychedelic drug assumed by somebody who is going to leach and suck some part of the body of another person, may penetrate the epidermal barrier and duplicate the same effects the drug itself provokes in the individual who assumes the drug itself prior. There is a very old study that records the time of penetration in the epidermal barrier of scrotum in man, and for this reason we have chosen to investigate upon the effects an hallucinogen (Elemi oil) can reproduce its effects similarly by applying (through leaching) the drug on the scrotum of other individuals. The subject who likes to make fellatio to volunteers is only one girl: she is not a nymphomaniac but a girl who have some extravagant and odd psychedelic phantasies and makes three fellatio to three volunteers.
\end{abstract}

Key words: Manila Elemi oil; Fellatio; Oral mucosa; Scrotum

\section{INTRODUCTION}

Elemi oil is extracted form the barks of various trees belonging to the Family of Burseraceae.Its scent is pleasant (citrus and fennel) and contains 30\% of fellandrene and elemol, but even some substances (elemicyn and amyrin) that behave as psychedelic or hallucinogen drug when assumed dissolved in milk or pure oil.(effectively the oleoresin is fully soluble in ether) [1].

There is a new fashion in youngest people that forecasts its assumption to have good trips and effectively their results resemble exactly the manifestations and present the same duration of mescalin, and for, it is worshipped by young psychonauts or sailors of the soul all over the world $[2,3]$.

Like the major part of hallucinogens its effect lasts from 2 days till 5-7 days and the concentration is very high in saliva, since the molecule is not soluble at the $\mathrm{pH}$ of the oral mucosa and adheres very well to mucosa since it is a waxy compound [4].
Effects and pharmacodynamic behaviors are similar to those evoked by mescaline [5].

Generally the dosage employed to have good trips is 20 drops of pure oleoresin dissolved in milk or oil and fascination and hallucination is ensured for almost 5 hours, even if traces of elemycin and elemol are retrievable in bloodstream and saliva for 2-3 days [6,7].

Here follows the detailed description of all the odd and psychedelic sensations a young who used it felt after having assumed Manila Elemi oil.

He recorded all the sensation he felt in the first 2 hours, lying on his bed in his room.

0:00 - drank in soymilk, really citrusy. Kind of a burn on the back of my throat when first drinking, but not bad.

0:10 - feeling really cloudy but in a good way, really nice body, still coming up.

0:15 - wow, haven't felt this good in such a long time. super dreamy euphoria, definitely not placebo.

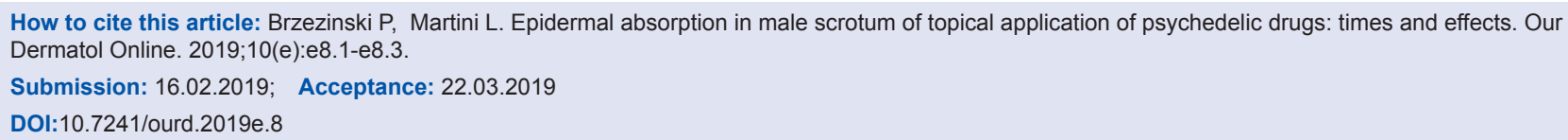


0:20 - Jesus I didn't think it would be this good. Listening to Pink Floyd Echos and music is like flowing through me. Really am loving this.

$0 ; 30$ - man this is really chill, kind of cloudy euphoria, hard to walk straight lol. I don't feel like I'm controlling my hands $8 / 10$ so far for this.

0:40 - ok so fractals are like all over my computer screen and peripheral vision. Apples taste like yes.

0:45 - real quick edit, going to go smoke and see what happens.

0:60 - After smoking feel suddenly energetic, but feel stupid almost lol. the best way to describe the feeling is like a flat mountain top but its really nice and sunny.

1:10 - time seems to go by really slow, $10 \mathrm{~min}$ from my last post felt like 2 hours. Geometric visuals fill computer screen or anything I focus on. Visual snow, even with eyes open really strong. Closed eye visuals make me feel like I'm running really fast, but like not moving vision swaying green red and white snow and lines when eyes closed. Wow, this is really fun.

2:00 - So it is starting to wear off now, still some fractals if you space out hard enough. Tons of fun, but there are sometimes pangs of hunger almost? But not really. All in all a trippy headspace that makes it easy to pass out on.

In this study we would like to show how the drug penetration through the penis and scrotum is very fast and that a fellatio can evoke the same hallucinations in the man to whom a woman is making it.

After a questionnaire it is very intriguing to discover that if a girl assumes the elemi oil and makes a real fellatio to his man, he will feel the same sensations felt by the girl, even If only after the first 15 minutes from the assumption of the psychedelic substance (the Manila Elemi oil).

Effectively there is an old paper [1] where the A.A. studied the drug absorption in vitro in abdomen and scrotum skin.

Absorption is completed after 15 minutes.

The A.A. [1] studied the permeability of scrotal and abdominal skin to topically applied substances in vitro using a method similar to that of Flesch, Satanove, and Brown [2]. Specimens of autopsy skin from abdomen and scrotum were taken from two separate patients. The sheets of skin were placed in the chambers with saline. Five per cent salicylic acid in lanolin was layered on the epidermal surface of each section and the sections incubated in a desiccator at $35^{\circ} \mathrm{C}$. They were tested for the penetration of salicylic acid with dilute ferric chloride at intervals of $15,30,60$, and 120 minutes. In every instance, on taking the unit apart, the rim of each specimen was tested with ferric chloride to rule out leakage around the edge of the skin. In order to test the amount of inhibition to absorption contributed by the dermis, a slice of dermis without epidermis was tested for absorption of salicylic acid in the same manner.

Penetration of liquid substances through penis and scrotal epidermis lasts less than 15 minutes, meanwhile the penetration through the abdomen epidermis lasts more than 2 hours.

The same A.A. added that volatile oils have not the same faith.

\section{MATERIALS AND METHODS}

For this purpose we have recruited 3 men $(27,34$ and $51 \mathrm{y}$. old) and a girl (27 y.) who desired to assume elemi oil and make a fellatio to the three men in diverse occasions and times in different days. We had to wait almost two entire days in order to be sure that the girl presented non elemycin in her saliva (or in her blood) and so we prepared the three encounters (all the 4 individuals were always present, to simulate the fight, as below) on Monday, Thursday and Sunday.

In effect, the girl liked to have psychedelic imaginations where a man was beaten by two other men and the injured man wanted to be comforted by her, through a complete fellatio.

The girl drunk 20 drops of elemi oil dissolved in soymilk and afterwards she began the fellatio to the man who had been beaten by the other companions. Psychedelic music was spread in the open space where all the drama was accomplished.

Now, 20 drops of elemi oil weight $0.8 \mathrm{~g}$ and $2.4 \%$ is represented by elemycin.

So the elemycin that remains in the saliva for 5 hours (minimum) is $0.0192 \mathrm{~g} \mathrm{[2].}$ 


\section{RESULTS}

After the fellatio (that lasted 45 minutes) we made the questionnaire to the man.

He answered so to our questions:

He felt after a quarter of hour an infinite euphoria. Afterwards he began to sneak his body following the fascinating rhythms of the psychedelic music and could not keep his hands still.

He ate an apple and refers its savor was superb and divine.

After the fellatio he desired to smoke a cigar.

The third man (51 y. old) wanted to smoke a cigarette and saw sunny mountains and was sure that the fellatio lasted more than 3 hours.

The youngest volunteer (27 y. old) achieved the step of eating the apple. He felt it very sweet but not very extraordinary.

\section{CONCLUSIONS}

It could be interesting to measure the surface of the three scrotum in order to understand if the area of application of the psychedelic substance interferes with the quickness of symptoms and sensations, but we had available only studies made in vitro. There is nothing analog retrievable in literature hitherto.

We suppose that age of the man who undergoes the fellatio depends strictly on the quickness of the sequence of the steps forecasted for the psychonaut.
It is obvious that the old man need more time to ejaculate and so he can reach the step of the virtual visions of the sunny mountains, even if sensations during the fellatio are less acute and impressive.

The young boy is concentrated more on the achievement of the complete orgasm and has not the chance to taste or define well the savor of a fruit.

\section{REFERENCES}

1. Graham Smith J, Fischer RW, Harvey B. The epidermal barrier: a comparison between scrotal and abdominal skin. J Invest Dermatol. 1961;36:337-43.

2. Broding HC, van der Pol A, de Sterke J, Monsé C, Fartasch $\mathrm{M}$, Brüning T. In vivo monitoring of epidermal absorption of hazardous substances by confocal Raman micro-spectroscopy. J Dtsch Dermatol Ges. 2011;9:618-27.

3. Martini L. A biological melange and a peculiar led light could be a thaumaturgic approach to defeat manifold types of folliculitis in man and woman. Our Dermatol Online. 2017;8:27-30.

4. De Gregorio D, Enns JP, Nuñez NA, Posa L, Gobbi G. d-Lysergic acid diethylamide, psilocybin, and other classic hallucinogens: Mechanism of action and potential therapeutic applications in mood disorders. Prog Brain Res. 2018;242:69-96.

5. Merle A, Villanueva C, Torres R. The composition of Manila Elemi oil. Flav Fragran J. 1993;8:35-7.

6. Ušjak L, Petrović S, Drobac M, Soković M, Stanojković T, Ćirić A, et al. Essential oils of three cow parsnips - composition and activity against nosocomial and foodborne pathogens and food contaminants. Food Funct. 2017;8:278-90.

7. Gu D, Fang C, Yang J, Li M, Liu H, Yang Y. Chemical composition and $\alpha$-amylase inhibitory activity of the essential oil from Sabina chinensis cv. Kaizuca leaves. Nat Prod Res. 2018;32:711-3.

8. Zhao L, Yang F, Yan X, Huo Z, Zhang G. Heavy metal concentrations in surface sediments and Manila clams (Ruditapes philippinarum) from the Dalian coast, China after the Dalian port oil spill. Biol Trace Elem Res. 2012;149:241-7.

Copyright by Piotr Brzezinski, et al. This is an open access article distributed under the terms of the Creative Commons Attribution License, which permits unrestricted use, distribution, and reproduction in any medium, provided the original author and source are credited.

Source of Support: Nil, Conflict of Interest: None declared. 